https://doi.org/10.24201/aap.2021.322

INFORME

\title{
China en 2020: Coronavirus y cambios en la relación con los países desarrollados
}

\section{China in 2020: Coronavirus and Changes in the Relationship with Developed Countries}

\author{
MARISELA CONNELLY \\ https://orcid.org/0000-0002-0201-9616 \\ El Colegio de México, A.C., México
}

Recepción: 30 de septiembre de 2020

Aceptación: 27 de octubre de 2020

Resumen: En 2020, China se ha enfrentado a graves problemas generados por la epidemia, convertida en pandemia de la covid-19. No sólo dentro del país, sino también por las reacciones negativas en el exterior, principalmente de Estados Unidos. También, en este año, los líderes chinos comprobaron que el llamado periodo de oportunidad estratégica, en el que el país pudo aprovechar las ventajas que le ofrecía el ambiente internacional de apertura, se había terminado. Las potencias desarrolladas, al ver su avance económico, el fortalecimiento de sus empresas en el exterior, su mayor participación en los asuntos internacionales, la confrontaron y le exigieron seguir políticas más equitativas que implicaban abrir más su mercado a productos extranjeros. Estados Unidos ha atacado a China de una manera que recuerda los años de la Guerra Fría, las declaraciones de funcionarios estadunidenses de alto nivel, rotundas y contundentes, muestran su preocupación por contener el avance de Beijing.

Palabras clave: China; pandemia; Hong Kong; economía; Estados Unidos. 
Abstract: In 2020, China faced serious problems caused by the epidemic, which became the Covid-19 pandemic. These problems were not only internal, but also because of negative reactions from abroad, mainly from the United States. Also this year, Chinese leaders found that the so-called strategic opportunity period, in which the country was able to take advantage of the international opening environment, was over. Developed countries have seen China's rise as a threat to its interests. They question the strength of Chinese companies abroad and Chinese involvement in international affairs. They ask for an opening of the Chinese market for their products. The United States has attacked China in a way reminiscent of the Cold War years, statements by high-level, outright, and hard-hitting US officials show concerns about containing Beijing's advance.

Keyworlds: China; pandemic; Hong Kong; economy; United States.

Los líderes chinos se enfrentaron a una problemática compleja desde finales de 2019 que los ha llevado a fortalecer el liderazgo del gobierno central y la figura de Xi Jinping, lo mismo que la autoridad del Partido Comunista Chino (PCCh). En el Cuarto Pleno del 19 Comité Central que se llevó a cabo del 28 al 31 de octubre de 2019, el énfasis fue puesto en cuestiones de seguridad nacional tanto en el territorio chino como en la Región de Administración Especial de Hong Kong. En el comunicado que se dio a conocer después de la reunión se afirma la necesidad de mejorar tanto las instituciones como el liderazgo del PCCh, las cuestiones relativas al estado de la economía y la relación con Estados Unidos. Se da énfasis al papel que deben de tener las empresas públicas como base de la economía y su desempeño (Mai y Zheng 2020).

El $1^{\circ}$ de octubre de 2019 se conmemoraron los 70 años del establecimiento de la República Popular China (RPCh) con un gran desfile militar en el que se desplegaron 15000 tropas, 160 aviones, 580 tanques y demás armamento moderno. En su discurso, Xi Jinping recordó la escena del $1^{\circ}$ de octubre de 1949, cuando Mao Zedong declaró, en ese mismo lugar, el establecimiento de la república popular. También señaló que el PCCh es el que ha llevado al país al éxito económico, siguiendo el camino del socialismo con características chinas y poniendo al pueblo en primer lugar. 
En comparación con la tendencia a recordar los tiempos maoístas, en los que se exaltaba la labor de héroes populares como Lei Feng, soldado del Ejército de Liberación Popular (EPL) que después de su muerte fue puesto de ejemplo por su amor y entrega al país y su gente, ahora se pone de ejemplo a una mujer, Huang Wenxiu, graduada en la Universidad Normal de Beijing, originaria del pueblo de Baise en Guangxi, al sur del país. Al graduarse regresó a trabajar a Baise como miembro del comité municipal del PCCh. Desde marzo de 2018 trabajó en el programa de alivio a la pobreza en el pueblo de Baini. Murió el 30 de junio de 2019 a la edad de 30 años al viajar por una carretera después de una lluvia intensa. Empezó la leyenda y el Comité Central del PCCh inició la campaña para aprender de Huang, propagar su historia en todos los niveles y seguir su ejemplo (Xinhua 2019).

Las reuniones anuales del Comité Nacional de la Conferencia Consultiva Política del Pueblo Chino, órgano principal de asesoría política del país, y la Asamblea Popular Nacional, órgano legislativo de China, que regularmente se realizan en el mes de marzo, se llevaron a cabo del 21 al 28 de mayo de 2020, retrasadas por la crisis sanitaria provocada por el coronavirus. El informe presentado por el primer ministro Li Keqiang dio cuenta de la situación económica y de las acciones que el gobierno tomaría para revitalizar la economía. Por primera vez, Li anunció que no establecería una meta de crecimiento económico en 2020 dadas las condiciones imperantes de incertidumbre en el desempeño de la economía y el comercio. Beijing adoptó un paquete económico de 4 billones de yuanes (US\$559 000 millones) para los fabricantes y comerciantes en 2020, el más grande plan de rescate hasta ahora; reducción de costos de las empresas que incluía exenciones de impuestos, baja de intereses bancarios y fondos para el bienestar social. El énfasis fue puesto en la creación de nuevos empleos urbanos para lograr bajar la tasa de desempleo, que se ubicó en 6\% en abril. Li Keqiang señaló que en tiempos extraordinarios se necesitaban esfuerzos extraordinarios: "Proveemos de agua para que el pez no muera" (China Daily 2020). Li indicó, además, que el déficit fiscal se elevaría al menos 3.6\% frente al 2.8\% del año anterior; la inflación prevista se sitúa en $3.5 \%$, mayor que en 2019 , que fue de $2.9 \%$. El gasto en defensa se elevaría en $6.6 \%$, quedando en 1.26 billones de yuanes.

La figura de Xi Jinping es la del líder máximo del PCCh, el hexin que guía al país hacia la consecución de sus metas: cohesión social que gira alrededor del partido, desarrollo de la 
economía en beneficio del pueblo, estabilidad política y social, y defensa de los intereses del país contra las amenazas externas. Nuevamente observamos una centralización del poder y la toma de decisiones en la persona de Xi. Sus palabras se convierten en la línea a seguir, por ello se publican extractos de sus discursos sobre temas que atañen a la situación interna y externa, y que enfatizan el papel central del PCCh y su líder, sin los cuales, el país no lograría salir adelante. En sesiones con representantes de las provincias que asistieron a las dos grandes reuniones, Xi dijo que se debían redoblar esfuerzos para mostrar al país como el mercado más grande del mundo y hacer clara la dirección estratégica de la reforma estructural. Resaltó las fortalezas del país: tiene un sistema industrial grande e integrado, con una capacidad manufacturera fuerte y una clase media de 400 millones de personas. China, señaló Xi, persistirá en el multilateralismo, la cooperación, la apertura y en su postura de mantener la estabilidad y continuidad de las cadenas de abastecimiento globales (Tang 2020b).

En julio de 2020, ante la preocupación por las políticas estadunidenses tendientes al desacoplamiento de su economía con la china, Xi Jinping se reunió con líderes empresariales dedicados a la producción de energía, químicos, chips, inteligencia artificial, internet de las cosas para pedirles que fueran patriotas y al mismo tiempo innovadores, en el sentido de alinear su estrategia de negocios con las necesidades del país.

\section{ECONOMÍA}

La economía de China se vio seriamente afectada por los efectos de las medidas tomadas para detener el avance de la covid-19, que implicaron un cierre de actividades y de reclusión obligatoria de la población en sus casas. De enero a marzo de 2020, la economía se contrajo por primera vez en décadas; el producto interno bruto (PIB) cayó $6.8 \%$ de acuerdo con el Departamento Nacional de Estadísticas del país, la primera contracción en el primer cuatrimestre desde que se empezó el registro en 1992 y la primera contracción de cualquier tipo desde 1976. La producción industrial cayó 1.1\% en marzo; las ventas al menudeo cayeron 15.8\%, el desempleo en las ciudades fue de 5.9\%. El Banco Central tomó medidas para reactivar la economía: cortó el interés en 20 puntos, elevó el radio de déficit fiscal, emitió bonos del tesoro especiales diseñados para ciertas políticas y proyectos, y por ello no se calculan dentro del déficit fiscal. Estas políticas servirían también para evitar el 
endeudamiento excesivo de los gobiernos locales. Para el segundo trimestre de 2020, la economía creció 3.2\%, mostrándose la tendencia hacia la recuperación.

La preocupación del gobierno por evitar estallidos sociales lo llevó a seguir políticas flexibles hacia la población de migrantes que vivían en las ciudades, precisamente para poder trabajar, y que ahora estaban desempleados (Tang 2020a). Las firmas industriales vieron disminuidas sus ganancias por la crisis sanitaria, sólo dos no reportaron pérdidas, la de alimentos y la del tabaco. Más de 460000 firmas chinas cerraron de manera permanente en el primer cuarto de 2020, 26000 corresponden al sector exportador (Wang 2020). El gobierno chino puso énfasis en el fortalecimiento de las empresas estatales, pues son consideradas el fundamento del socialismo y la revitalización de la economía. Ello explica la necesidad de incrementar su competitividad, innovación y capacidades. Además, el PCCh ha reforzado su presencia dentro de ellas, mantiene células que controlan la toma de decisiones y el nombramiento de personal clave. Todo esto es una vuelta al control férreo del partido sobre estas empresas.

El comercio exterior de China decreció 3.2\% en el primer semestre de 2020 en relación con el mismo periodo del año anterior. Los países que conforman la Asociación de Naciones del Sudeste de Asia (ANSEA) se convirtieron en sus socios comerciales más importantes, con $14.7 \%$ de su comercio exterior. En abril, Taiwán, Vietnam, Tailandia e Indonesia compraron 50\% más de productos chinos que en el mismo periodo de 2019 (Moak 2020). Las exportaciones chinas de textiles se incrementaron $32.4 \%$ a raíz de la pandemia; lo mismo los materiales médicos y medicinas, que se incrementaron en $23.6 \%$, y el equipo médico en un $46.4 \%$, todo en relación con el desempeño del mismo periodo del año anterior (Renmin Ribao, julio 14, 2020).

A raíz de la baja en el precio del petróleo, propiciada por la guerra de precios entre Rusia y Arabia Saudita, que ocupan el segundo y tercer lugares como productores, respectivamente, el gobierno chino aprovechó para comprar más; en marzo sus importaciones crecieron 4.5\% en relación con el mismo mes de 2019: 9.68 millones de barriles al día de acuerdo con su aduana. China se ha convertido en el mayor importador de petróleo en el mundo. En los primeros dos meses de 2020, las importaciones chinas de petróleo saudí se 
elevaron $26 \%$ en relación con el mismo periodo del año anterior, en tanto que la compra de petróleo ruso se elevó 11\% (Asia Times, 21 abril 2020).

\section{EL CORONAVIRUS Y SUS ESTRAGOS EN CHINA}

En diciembre de 2019, en la ciudad de Wuhan, provincia de Hubei, los hospitales locales empezaron a detectar un tipo de neumonía atípica en algunos pacientes. Enviaron muestras del patógeno a laboratorios locales para su análisis y compartieron información con la Academia China de Ciencias Médicas, pero no fue sino hasta finales de mes cuando el Hospital Hubei notificó sobre los hechos al Departamento de Control de Enfermedades de la Comisión de Salud Municipal de Wuhan y al gobierno provincial de Hubei. Para el 30 de diciembre, la Comisión Nacional de Salud fue informada de lo que sucedía, e inmediatamente organizó dos grupos de expertos para que viajaran a Wuhan y trabajaran con las autoridades locales. El 7 de enero, de acuerdo con la versión de la Organización Mundial de la Salud (OMS), los funcionarios chinos anunciaron que habían logrado identificar el nuevo virus (Swaine 2020a; Dotson 2020a).

La Comisión Municipal de Salud advirtió al personal que participaba en la atención de enfermos no proporcionar información sin autorización, lo que dio pie a la detención del doctor Li Wenliang, quien había empezado a comentar en redes sociales chinas sobre el virus y sus efectos en la salud. Las autoridades, al enterarse, le pidieron al doctor Li que desmintiera la información que había difundido; poco tiempo después murió a consecuencia del virus. ${ }^{1}$ Al levantarse una ola de comentarios negativos, el gobierno decidió exonerarlo póstumamente. Como parte del control de información, el 30 de diciembre las autoridades de salud le comunicaron a los laboratorios privados que realizaban pruebas sobre el virus que dejaran de hacerlo y no comentaran sobre lo investigado. La Comisión Nacional de Salud, para el 3 de enero, repitió lo mismo. Se dio un proceso en el que se usó un criterio estricto sobre los diagnósticos con requerimientos de aprobación burocrática rígida, lo que ralentizó las acciones a tomar.

\footnotetext{
${ }^{1}$ Li Wenliang era oftalmólogo que trabajaba en un hospital de Wuhan. Desde finales de diciembre notó que ingresaban pacientes con síntomas parecidos al SARS de 2003. Li recibió una visita de la policía que lo condujo a la comisaría local en donde lo obligaron a firmar un documento en el que se comprometía a no divulgar información confidencial ni esparcir rumores.
} 
Así iniciaba una crisis en un contexto donde miles de personas viajaban en toda China para festejar con sus familias el año nuevo chino. Los funcionarios locales deseaban tener una prueba contundente sobre el virus y su letalidad antes de sonar la alarma. El 18 de enero, un grupo de expertos de la Comisión Nacional de Salud, encabezado por Zhong Nanshan y Li Lanjuan viajó a Wuhan, en donde detectaron la rapidez con la que se esparcía el virus de persona a persona. A su regreso a Beijing reportaron de la situación a la viceprimera ministra Sun Chunlan, encargada de los temas de salud pública dentro del Consejo de Estado (Swaine 2020a). Después, en una reunión ejecutiva presidida por el primer ministro Li Keqiang decidieron crear una coordinación central y de alto nivel para la prevención y control del virus bajo Sun Chunlan. El 20 de enero se hizo público el reporte de los expertos, cuando Xi Jinping se encontraba en Yunnan, de regreso de su viaje a Myanmar y recibió información sobre la gravedad de la crisis. Sun Chulan viajó a Wuhan con instrucciones de Xi de cerrar la ciudad y evitar que la gente que había viajado entrara de nuevo.

El 25 de enero, Xi Jinping presidió una reunión del Comité Permanente del Politburó del PCCh y mostró gran preocupación por las noticias sobre los contagios del virus fue el momento en el que decidió enfrentar la crisis de manera frontal: formación de un Grupo Dirigente para dar Respuesta a la Epidemia, encabezado por Li Keqiang, y enviar de nuevo a Sun Chulan a Wuhan para comunicar las directivas del liderazgo nacional a los funcionarios locales (Dotson 2020b; Swaine 2020a). Li Keqiang también visitó Wuhan; además, presidió reuniones en las que se trató el tema del coronavirus en el Grupo Dirigente, en el Centro Chino para el Control y Prevención de Enfermedades y la Academia China de Ciencias (Pei 2020a; Oliver 2020).

El 28 de enero, Xi Jinping sostuvo una entrevista con el director general de la OMS, Tedros Adhanom Ghebreyesus, después de la cual fue reportado que Xi había dicho que él estaba a cargo directamente del combate a la crisis epidémica. El 3 de febrero Xi Jinping dio un discurso en el que hizo un recuento de su intervención en la crisis: dijo que desde el 7 de enero había girado instrucciones sobre la contención del virus y que ésa había sido su prioridad desde el 23 de enero. Describió la batalla contra el virus como "guerra del pueblo" recordando los tiempos maoístas (Xinhua 2020b); reconoció que las medidas que se estaban tomando para controlar la epidemia tendrían efectos negativos sobre la economía y el 
comercio. Criticó a los funcionarios locales por su formalismo y burocracia y advirtió que se castigaría a los culpables. Todo ello con el fin de evitar críticas al gobierno central por no actuar desde los primeros indicios de la gravedad del virus.

El 5 de febrero, Xi Jinping llamó a atacar las actividades ilegales y crímenes, que iban desde resistir la prevención epidémica y esfuerzos de control, ataques a trabajadores de salud, manufactura y venta de productos falsos como material médico y cubrebocas y la propagación de rumores. El 10 de febrero Xi estuvo en una videoconferencia con funcionarios públicos de Wuhan; también realizó una inspección a dos barrios de Beijing y dos hospitales. El 12 de febrero Xi presidió la reunión del Politburó, en la que probablemente fue decidida la suerte de los funcionarios locales a los que se les hacía responsables de no haber informado a los líderes centrales sobre la crisis, en tiempo y forma. Zhang Lin, secretario del partido para la Comisión de Salud Pública de Hubei, y Liu Yingzi, director del mismo, fueron removidos de sus cargos. Jiang Chaoliang, secretario del partido para la provincia de Hubei, fue remplazado por Ying Yong, quien previamente sirvió como alcalde de la ciudad de Shanghái y subsecretario del partido en esa ciudad. Ma Guoqiang fue depuesto como secretario del partido en Wuhan y remplazado por Wang Zhonglin, que había sido secretario del partido en la ciudad de Jinan en Shangdong. Al mismo tiempo, los líderes del partido establecieron las medidas que serían tomadas para combatir al virus: elevar la capacidad de hospitales en el país de tal forma que no dejaran a nadie sin atención; reducir la tasa de infección mediante el fortalecimiento de la prevención y el control, bloqueando la trasmisión; mejorar los tratamientos para los pacientes a través de recursos y tecnología médica e intensificar el monitoreo de salud del personal médico (Xinhua 2020a).

Para el 23 de febrero, Xi Jinping presidió una gran reunión de trabajo con altos líderes en Beijing en la que dio un discurso que de forma remota también fue escuchado por 170000 funcionarios a lo largo de cada pueblo y regimiento militar del país. Xi describió su involucramiento en la toma de decisiones para enfrentar el brote epidémico. Destacó los efectos que la crisis sanitaria y las medidas de reclusión forzada de la población habían tenido en la economía; caracterizó estos retos como manejables y de corto plazo, la actuación del Comité Central del PCCh que hizo un análisis de la situación actuó a tiempo y tomó medidas efectivas para contener el avance de la epidemia (Pei 2020a; Swaine 2020a). 
El gobierno realizó una movilización de recursos financieros y médicos dirigidos a la ciudad de Wuhan y otras áreas afectadas, envió grupos médicos del ELP y de la Comisión de Salud China. El Banco de Desarrollo de China destinó un préstamo por 21000 millones de yuanes (US\$283.3 millones) como préstamo de emergencia. El Ministerio de Finanzas destinó 1000 millones de yuanes (US\$144.2 millones); las compañías Tencent, Lenovo, Xiaomi, entre otras, ofrecieron contribuciones de fondos y de utensilios médicos (Oliver 2020). El ELP y la Policía desempeñaron un papel muy importante en el control de la población para que acatara las medidas relativas a la reclusión en sus casas y hacer efectiva la cuarentena.

La ciudad de Wuhan, de 11 millones de habitantes, sufrió el cierre al tránsito de personas, suspensión del transporte público, prohibición de entrada y salida de vehículos particulares; además, 12 ciudades de la provincia de Hubei emitieron restricciones de viaje. Con estas medidas draconianas, de fines de febrero a abril el virus fue contenido, las autoridades centrales junto con las locales continuaron coordinando sus acciones para lograr un balance entre el control de la epidemia y sus efectos en la economía. El 27 de marzo, el Politburó del PCCh se reunió para discutir los avances en el combate al virus y en la estabilización de la economía (Renmin Ribao, marzo 28, 2020).

Xi Jinping continuó con sus viajes por el país tratando de mostrar el trabajo realizado por el partido para combatir la epidemia y continuar con el desarrollo económico y social. El 29 de marzo viajó a la provincia de Zhejiang, especialmente a Chuanshan, área portuaria del Puerto Ningbo Zhoushan. A principios de abril, Xi Jinping, Li Keqiang y demás líderes rindieron tributo a todos los que murieron por la epidemia de covid-19, con el ondeo de las banderas a media asta en todos los edificios públicos. De acuerdo con la Comisión de Salud, fueron confirmados 81639 casos y 3326 muertos en el país (Renmin Ribao, abril 4, 2020).

En el mes de junio apareció un brote de la covid-19 en la ciudad de Beijing e inmediatamente las autoridades tomaron medidas para detectar los casos y realizar pruebas masivas de detección del virus. Más de 356000 personas fueron sometidas a la prueba (Chen 2020; Zhuang y Ting 2020).

La epidemia de la covid-19 fue una dura prueba para el gobierno chino, no solamente por los efectos en la salud de sus ciudadanos sino por los estragos que la economía sufrió con 
las medidas tomadas para poder controlarlo. Como veremos más adelante, la propagación del virus en el mundo complicó las relaciones de China con países como Estados Unidos y la Unión Europea, que criticaron las políticas del gobierno, acusándolo de esconder el brote y no combatirlo desde su inicio.

\section{CHINA, COVID-19 Y EL MUNDO}

En 2020, China enfrentó un ambiente internacional hostil debido a que Estados Unidos y países desarrollados de la Unión Europea la vieron como un rival en ascenso que se aprovechó de la apertura para obtener ganancias comerciales y, además, incrementar la inversión en fusiones y compras de compañías dedicadas a la tecnología. El enfrentamiento entre China y Estados Unidos se agudizó por la expansión del coronavirus por todo el mundo y los estragos que hacía tanto en la población como en la economía. El gobierno chino se puso a la defensiva y encomendó a sus diplomáticos defender al país de estos ataques y mostrar que estaban dispuestos a ayudar para resolver los problemas generados por la expansión del virus. Creó el fenómeno de los “Guerreros lobos” (战狼), diplomáticos chinos que, con una agresiva propaganda y retórica dirigida a gobierno e individuos en el exterior, presentaban los esfuerzos de su gobierno para acabar con la epidemia en el país, y de cómo logró controlarla. Pero desde marzo también siguieron una política de colaboración con los gobiernos de diferentes países: enviaron, en varios vuelos, material médico, mascarillas y ayuda médica; ofrecieron colaboración científica y provisión de información a Italia y otros países europeos como República Checa, Serbia, España, entre otros. Huawei ofreció donar equipo de protección personal a Irlanda (Wong, B. 2020).

En este sentido, en las reuniones como la del G20, realizada en el mes de marzo vía videoconferencia, el presidente Xi Jinping enfatizó en la política seguida por su gobierno ante la pandemia, pidió unidad y solidaridad para fortalecer los esfuerzos internacionales para controlar la expansión del virus y, al mismo tiempo, trabajar para reactivar las economías afectadas por las medidas de reclusión de la población (Lau y Churchill 2020; Cong y Li 2020). El apoyo a la Organización Mundial de la Salud se vio reflejado en los aportes económicos de China, cuando Estados Unidos anunciaba la suspensión de sus aportaciones a esta organización al considerarla como brazo de Beijing para manipular a la opinión 
internacional y desinformar ante el avance del virus. El gobierno chino donó US\$30 millones a la OMS sumados a los US\$20 millones que le había dado en el mes de marzo. En su discurso ante la reunión 73 de la Asamblea de la OMS, en el mes de mayo, Xi se refirió a la necesidad de fortalecer la gobernanza global en salud pública y el papel de la OMS, como organización que debía dirigir los esfuerzos, para así poder responder de manera rápida y efectiva a la emergencia de salud, que consideró como la más seria desde la segunda Guerra Mundial. Anunció que su país destinaría US\$2 000 millones de dólares para ayuda a países en desarrollo en su lucha contra la covid-19, que sería distribuida en los dos años siguientes (Lau 2020; Swaine 2020b). También Xi habló del papel que debe desempeñar la Organización de Naciones Unidas en la distribución de la ayuda humanitaria, principalmente entre los países en vías de desarrollo (Renmin Ribao, mayo 18, 2020).

\section{RELACIONES CON ESTADOS UNIDOS}

El enfrentamiento de China con Estados Unidos fue catalogado por Henry Kissinger como una nueva Guerra Fría, y es que la relación entre China y Estados Unidos ha entrado en su fase de mayor competencia por el liderazgo internacional que se manifiesta en las disputas relativas a tecnología, comerciales, desencuentros en el Mar del Sur de China, la cuestión de Taiwán, la imposición de la Ley de Seguridad en Hong Kong, respeto a los derechos de los uigures en Xinjiang y sobre la pandemia de la covid-19.

En el tema relativo al comercio bilateral entre China y Estados Unidos, que se vio afectado desde que Trump, en 2018, empezó a imponer aranceles a las importaciones de acero y aluminio procedentes de China, lo que golpeó a empresas estadunidenses como embotelladoras de latas de refresco y fabricantes aeronáuticos, en total Washington ha impuesto aranceles sobre productos chinos por valor de 360000 millones de dólares (sobre un total de 452200 millones de dólares importados en 2019). China, por su parte, ha sancionado los productos que compra a Estados Unidos por 110000 millones de dólares. Con las medidas que tomó el gobierno de Trump se pudo reducir el déficit comercial con China en $18 \%$ en 2019 , pero ha tenido como consecuencia el perjuicio de empresas y consumidores de Estados Unidos. Los países beneficiarios de la guerra comercial han sido Vietnam y México. 
Las negociaciones para alcanzar consensos sobre la llamada "Fase Uno" del acuerdo comercial entre China y Estados Unidos continuaron, y el 5 de septiembre el representante de Comercio de Estados Unidos, Robert Lighthizer, y el encargado del Departamento del Tesoro, Steven Mnuchin, sostuvieron una conversación telefónica con el vicepresidente Liu He. Esto dio pie a que el presidente Trump anunciara que retrasaría la puesta en práctica de la imposición de $5 \%$ de incremento de aranceles a productos chinos, con valor de US\$250 000 millones; China reciprocó esta acción haciendo excepciones de tarifas a productos estadunidenses. Del 19 al 20 de septiembre de 2019 una delegación china encabezada por el viceministro de finanzas, Liao Min, viajó a Washington y sostuvo rondas de discusión con sus contrapartes. Siguieron otros intercambios en el mes de octubre, y el 14 de ese mes, Mnuchin comunicó que ya se había alcanzado un acuerdo. El 25, Liu He se comunicó con Mnuchin y Ligththizer. El 14 de noviembre, China anunció que había eliminado las prohibiciones para la compra de aves de corral provenientes de Estados Unidos. El 13 de diciembre los dos gobiernos anunciaron que habían llegado a consensos que llevaron a la aceptación de la "fase uno" del acuerdo comercial, que incluía también el tema relativo a la propiedad intelectual, transferencia de tecnología, agricultura, servicios financieros, comercio y resolución de disputas.

En enero, China y Estados Unidos firmaron la fase uno del acuerdo comercial que reducirá algunas tarifas y que impulsa la compra de bienes y servicios estadunidenses por parte de Beijing. El presidente Donald Trump y el vicepresidente Liu He suscribieron el documento de 86 páginas durante una reunión en la Casa Blanca (Swanson y Rappeport 2020). No obstante el avance, quedó pendiente para la fase dos la discusión sobre los subsidios que el gobierno de China otorga a sus empresas. En este acuerdo, China se comprometió a importar, en dos años, 200000 millones de productos y servicios estadunidenses, y, además, a tomar medidas efectivas para detener el robo de tecnología y secretos corporativos; incluye también el acceso de compañías estadunidenses al mercado financiero chino. En mayo, vía telefónica, Liu He, por parte de China, y Robert Lighthizer, por parte de Estados Unidos, acordaron implementar el acuerdo comercial que se puso en vigor el 14 de febrero (Bermingham 2020). 
El 27 de abril de 2020, Estados Unidos hizo pública la imposición de nuevas restricciones a las exportaciones chinas, incluidos los componentes de aeronaves civiles y artículos relacionados con semiconductores. Las nuevas normas exigirán que las firmas de Estados Unidos que vendan ciertos artículos a entidades militares chinas, incluso para uso civil tendrían que solicitar una licencia, eliminando la excepción que permitía que ciertas tecnologías fueran exportadas sin licencia aun si la venta era a entidades militares. Estas normas afectan a la industria de semiconductores y de aviación civil. El gobierno estadunidense publicó un tercer cambio en las normas que obliga a las compañías extranjeras que envían ciertos bienes estadunidenses a China, a buscar la aprobación de Washington, además de la de sus propios gobiernos (Reuters, 27 de abril 2020).

El 8 de mayo, Liu He y Robert Lighthizer junto con el secretario de Tesoro, Steven Mnuchin, sostuvieron una conversación telefónica en la que señalaron que se esforzarían por crear condiciones favorables para la puesta en práctica de la fase uno del acuerdo económico y comercial. El 12 de mayo el gobierno chino anunció que eximiría de aranceles aduaneros adicionales a 79 productos provenientes de Estados Unidos, como plaquetas de silicio utilizadas en la electrónica, desinfectantes de uso médico y las denominadas "tierras raras", minerales indispensables en la alta tecnología. Estaría vigente por un año a partir del 19 de mayo.

El 17 de junio, Mike Pompeo, secretario de Estado de Estados Unidos, y Yang Jiechi, enviado especial chino de alto nivel, se reunieron en Hawái para dialogar sobre los problemas en la relación. Solamente Yang declaró que la reunión fue constructiva, en tanto que Pompeo dijo que había dejado en claro la necesidad de que hubiera reciprocidad en las acciones referentes a comercio, seguridad y diplomáticas; además, destacó la posición de Washington frente a la crisis producida por la covid-19: el imperativo de transparentar e intercambiar información sobre el origen y el desarrollo de la pandemia, y así prevenir rebrotes $(\mathrm{Wu}$, Huang y Zheng 2020).

En mayo, Washington limitó el acceso de la empresa Huawei a insumos producidos de forma directa con software o hardware estadunidense. No obstante, Washington aseguró que la empresa había esquivado las medidas usando a terceros. El presidente Trump anunció que se tomarían medidas para impedir que accediera a microprocesadores producidos con 
tecnología de su país y agregó 38 compañías afiliadas a Huawei, en 21 países, a la lista negra, de manera que pasaron a ser consideradas una amenaza para la seguridad. El gobierno estadunidense argumenta que no sólo Huawei sino otras compañías chinas tienen vínculos con el ELP. El gobierno chino respondió que pondría en su lista de entidades no confiables a las empresas Qualcomm, Apple y Cisco.

La situación generada por la expansión del coronavirus en el mundo, y en especial en Estados Unidos tensó aún más la relación bilateral. El 18 de abril Donald Trump señaló que el gobierno chino enfrentaría las consecuencias si era responsable de esparcir la covid-19, pues el virus podría haber surgido de un laboratorio virológico ubicado en las cercanías de Wuhan. Pompeo pidió al gobierno de Beijing aceptar una inspección independiente para encontrar el origen del virus (Lanyon 2020). Beijing respondió a través de Geng Shuang, portavoz del Ministerio de Relaciones Exteriores, quien señaló que toda la comunidad internacional debía trabajar para combatir el virus. A su vez, Cui Tiankai, embajador de China en Estados Unidos, acusó a los políticos de ese país de ignorar la opinión de los científicos. Zhao Lijian, funcionario de rango medio en el Ministerio de Relaciones Exteriores, dijo públicamente que el virus había sido llevado a Wuhan por soldados estadunidenses. El presidente Trump empezó a referirse a la covid-19 como “el virus chino”. En la reunión del G7 del 25 de marzo, Pompeo lo llamó “el virus de Wuhan”.

La escalada de ataques hacia China se llevó a las plataformas chinas WeChat y Tiktok, que pertenecen a las compañías Tencent y ByteDance, respectivamente, y que son muy populares entre los estadunidenses. Según la orden ejecutiva de Trump del 6 de agosto, ByteDance tendría que vender a una compañía del país las operaciones de Tiktok, pues temía que los datos de 100 millones de ciudadanos que la usaban pudieran llegar a manos de funcionarios del gobierno chino (Deng y Chen 2020).

En 2019, las noticias sobre el confinamiento de grupos de la etnia uigur de Xinjiang, de origen musulmán, en campos de reeducación, para que dejaran sus costumbres machistas con respecto al trato de sus mujeres, dio pie a críticas de los funcionarios de Estados Unidos. El 8 de octubre, Mike Pompeo anunció que el gobierno impondría restricciones al otorgamiento de visas a funcionarios chinos involucrados en la represión y violación de los derechos humanos de los uigures. El Departamento de Comercio de Estados Unidos elaboró 
una lista de 28 compañías chinas, de funcionarios de gobierno y de seguridad, que supuestamente estaban involucrados en esta operación. La Embajada china en Washington envió su protesta por la intromisión en los asuntos internos del país. El 17 de junio de 2020, Trump transformó en ley The Uighur Human Rigts Policy Act y se imponían sanciones a compañías e individuos vinculados a la violación de los derechos humanos de los uigures (Albert 2020a). El Departamento del Tesoro también estableció sanciones contra funcionarios y entidades chinos que incluían a Chen Quanguo, secretario del PCCh en Xinjiang y miembro del Politburó; también a Zhu Hailun y Wang Minshang, encargados de la seguridad en la región. En respuesta, China tomó medidas similares contra funcionarios y legisladores estadunidenses que apoyaban estas medidas, como los senadores Marco Rubio y Ted Cruz (Renmin Ribao, julio 14, 2020).

La escalada de sanciones y represalias continuó. El 14 de julio, Trump anunció el término del programa Fulbright para China, que con sus becas incentivaba el intercambio académico. Cientos de participantes en este programa protestaron y criticaron la decisión, sobre todo aquellos que ya tenían sus preparativos hechos para el intercambio de 2020-2021. En ese mismo mes, el gobierno de Estados Unidos ordenó el cierre del Consulado de la RPCh en Houston, argumentando que era un centro de espionaje del ELP y del gobierno chino. Este consulado fue el primero que se estableció en el país, en 1979. El personal recibió la nota diciendo que tenía 72 horas para desocuparlo. El gobierno chino señaló que esta acción equivalía a una degradación de la relación bilateral y que tomaría medidas (Renmin Ribao, julio 22, 2020). El 23 de julio, Beijing ordenó el cierre del consulado estadunidense en Chengdu diciendo que el personal estaba realizando actividades que interferían en los asuntos domésticos del país. Para septiembre, Pompeo anunció una serie de restricciones a la labor de los diplomáticos chinos en Estados Unidos, como solicitar permiso del Departamento de Estado para visitar universidades y reunirse con funcionarios locales, así como para organizar eventos culturales de más de 50 personas fuera de las propiedades de la misión diplomática.

A raíz de los acontecimientos violentos en la Región Administrativa de Hong Kong (RAEHK) y la promulgación de la Ley de Seguridad Nacional de Hong Kong firmada por Xi Jinping, el 30 de junio el gobierno de Trump, a través de Pompeo, condenó la decisión; un mes después Trump declaró que tenía la intención de poner fin al trato preferencial que 
se le otorgaba a Hong Kong, como el tener aduanas separadas de las de China. El 14 de julio, Trump firmó el documento en el que pedía sancionar a individuos y entidades que contribuían a la erosión de la autonomía de Hong Kong. El Departamento del Tesoro impuso sanciones a funcionarios chinos y a la jefa ejecutiva de la RAEHK, Carrie Lam. El gobierno chino condenó estas acciones y señaló que la puesta en vigor de la Ley de Seguridad Nacional era necesaria para para mantener el orden en Hong Kong (Talley y Craymer 2020).

Taiwán volvió a ser foco de atención dentro de la relación China-Estados Unidos. La isla está gobernada desde 2016 por el Partido Democrático Progresista a través de la presidenta Cai Yingwen, quien en enero de 2020 ganó las elecciones para un segundo periodo. Cai se ha resistido a aceptar el "principio de una sola China", requisito indispensable que el gobierno chino dispone, para poder establecer un diálogo. El gobierno estadunidense ha mostrado su simpatía hacia Cai, sobre todo porque en la isla se tomaron las medidas adecuadas y contundentes para controlar la expansión de la covid-19, sin violentar los derechos de los habitantes. El gobierno de Beijing nuevamente bloqueó la petición de Taiwán de asistir como observador a la reunión anual de la OMS. En tanto que Estados Unidos le dio su apoyo y no sólo eso, adicionalmente Pompeo y otros funcionarios felicitaron a Cai cuando inició su segundo periodo de gobierno, lo que molestó a China, aparte de la venta de armamento estadunidense a la isla, que Trump anunció, con un valor de US\$189 millones, y después, en julio, un paquete por US\$620 millones destinados a extender el periodo de operación de los misiles Patriot que ya tenía Taiwán. Para agosto, el gobierno taiwanés finalizó la compra de jets de combate F-16 a Lokhead por US\$62 000 millones (Wong, E. 2020).

En agosto, el secretario de servicios de salud de Estados Unidos, Alex Azar visitó Taiwán y se entrevistó con Cai. Firmó una declaración conjunta con el ministro de Salud de la isla, en la que reafirmó la cooperación para enfrentar las amenazas a la salud global. El 31 de ese mes, Estados Unidos anunció el diálogo comercial, económico bilateral, enfocado a semiconductores, salud y energía. En septiembre, el subsecretario de Estado, Keith Krach, viajó a Taiwán para sostener conversaciones con Cai Yingwen. Krach era el funcionario de más alto nivel que mantenía un diálogo con los representantes de la isla en 41 años. El pretexto para la visita fue asistir al memorial por la muerte de Li Denghui, líder político que 
llevó a cabo el proceso de democratización de la isla y que propició el triunfo de la oposición en 2000, no obstante que él era miembro del Guomindang, o Partido Nacionalista, que había gobernado desde 1949 (Chung 2020).

En el Mar del Sur de China también se han dado confrontaciones entre China y Estados Unidos. De enero a marzo, la marina estadunidense realizó cuatro operaciones destinadas a mostrar su posición sobre la libertad de navegación en esas aguas. A mediados de abril, Trump envió dos barcos de guerra a la zona reclamada tanto por China como por Malasia y Vietnam. El 24 de abril, Pompeo mandó un mensaje en video a los ministros del exterior de países del sudeste de Asia diciéndoles que el gobierno de Xi trataba de intimidarlos para que no desarrollaran los yacimientos de hidrocarburos en el área en disputa. Para mediados de julio, Pompeo y el subsecretario de Estado, Michael Stilwell, tomaron una posición tajante, apoyando a los países que tienen disputas con China. Sus buques de guerra, como el Nimitz y el Reagan, aparecieron en las aguas en disputa. El gobierno chino, por su parte, continúa defendiendo su posición y lleva a cabo ejercicios militares para mostrar su fuerza y compromiso en la defensa de los territorios que considera suyos (Huang 2020).

El enfrentamiento entre Estados Unidos y China va más allá de las cuestiones señaladas, es una lucha por el poder global; el gobierno de Donald Trump ve en el país asiático un rival y, por ello, tomó la decisión de pararlo y obstaculizar su ascenso. El 20 de mayo salió a la luz la estrategia del gobierno estadunidense hacia China, titulada United States Strategic Approach to the People's Republic of China (White House mayo 2020) en la que afirma que el Partido Comunista Chino ha optado por explotar las reglas abiertas y libres e intenta rediseñar el orden internacional para favorecer sus intereses. De enero a agosto, Trump trató de convencer a la audiencia interna y del exterior de que China es una amenaza para la democracia.

El 4 de mayo un funcionario de seguridad nacional, Matt Pottinger, dio una conferencia en un evento organizado por la Universidad de Virginia; su discurso fue en chino. Esa fecha marcaba el aniversario del movimiento del 4 de mayo de 1919 en China, el cual, según dijo, mostró el coraje y decisión de los chinos para defender sus ideales democráticos (Pottinger 2020). El 16 de julio el procurador general, William Barr, en su discurso Remarks on China Policy, dado en el Museo Presidencial Ford, en Grand Rapids, Michigan, presentó 
a China como el país que usaba sus políticas comerciales, industriales y de espionaje para tratar de sobrepasar a Estados Unidos como superpotencia económica, y advirtió sobre la dependencia de su país respecto a China (Barr 2020).

El 23 de julio, Mike Pompeo dio también un discurso en el Museo Biblioteca Presidencial Richard Nixon, titulado Communist China and the Free World Future, en el que afirmó que Xi Jinping deseaba alcanzar la hegemonía mundial y el dominio del comunismo chino. Pidió a los países formar una nueva alianza de democracias, cuyo objetivo sería cambiar a la China comunista y empoderar al pueblo chino para que realice ese cambio (Pompeo 2020).

\section{CHINA Y LA UNIÓN EUROPEA}

El gobierno chino actuó de manera rápida y contundente para ayudar a países europeos afectados por la pandemia de la covid-19, como es el caso de Italia, que recibió ventiladores, máscaras, trajes protectores y materiales de prueba. También llegaron doctores chinos para dar apoyo en la emergencia. Huawei envió material biomédico, además propuso al gobierno italiano realizar la conexión de sus hospitales a través de la nube para facilitar sus tareas (Cristiani 2020). Pero gobiernos como los de Francia y Alemania cuestionaron la falta de transparencia del gobierno chino sobre el origen del coronavirus. Para contrarrestar los ataques a China, el ministro de Relaciones Exteriores, Wang Yi, realizó un viaje a varios países europeos; enfatizó en la posición de su país ante las críticas, mostrando que, para ellos, lo importante era la cooperación para acabar con la pandemia (Albert 2020b).

Además del problema por la covid-19, China y los países europeos mantienen una discusión sobre cuestiones de inversión y comercio. Estos países desean que el mercado chino se abra más para que puedan incrementar sus exportaciones hacia China, pero el gobierno chino ha mantenido su posición de hacerlo paulatinamente (Deutsche Welle 2020). Angela Merkel señaló en una reunión virtual con Xi Jinping que el país asiático se ha visto fortalecido en los últimos años, logrando tener una economía robusta, por tanto, la reciprocidad era necesaria para que las relaciones estén bajo piso parejo (Hein von 2020). 
El tema de violación a los derechos humanos en China también fue punto de controversia y de discusión entre los líderes chinos y europeos: la cuestión de Hong Kong y Xinjiang salió a relucir en las pláticas, pidiendo al gobierno que diera marcha atrás a sus políticas represivas. Como es costumbre, los líderes chinos argumentaron que son políticas internas y, por tanto, no pueden aceptar la intervención del exterior.

El asunto de bloquear a Huawei y la construcción de las redes $5 \mathrm{G}$ en varios de estos países sufrió un descalabro cuando líderes como Macron en Francia tomaron medidas para sacar a esta compañía china en unos años; lo mismo sucedió en Gran Bretaña.

La Unión Europea, al igual que Estados Unidos, ve a China como un competidor al que deben parar en su carrera por convertirse en superpotencia.

\section{HONG KONG: SITUACIÓN POLÍTICA Y ECONÓMICA}

Desde 2014, en la Región de Administración Especial de Hong Kong (RAEHK) se han manifestado sus habitantes pidiendo una apertura política que les permita participar de manera directa en la elección de sus autoridades. El jefe ejecutivo es elegido por un grupo en el que se encuentran representados diferentes sectores de la sociedad hongkonesa y de órganos legislativos de China. Además, los problemas económicos han mostrado, cada vez más, el grado de desigualdad y las pocas oportunidades de movilidad social, que los jóvenes ven como un escenario poco propicio para su desarrollo. En 2019 fue anunciada la Ley de Extradición, por la cual un detenido en Hong Kong podría ser extraditado a Beijing para ser enjuiciado, lo que ponía en duda la autonomía judicial de la RAEHK. Nuevamente las protestas se hicieron visibles en las calles de Hong Kong cada vez de manera más violenta, llegando a ocupar por la fuerza el edifico del Consejo Legislativo. Finalmente, la ley fue retirada; no obstante, las protestas siguieron, esta vez pidiendo la destitución de Carrie Lam, la jefa ejecutiva, la liberación de los detenidos y la elección de ese puesto por sufragio universal. El gobierno central apoyó a Lam y evitó intervenir directamente en la supresión de las protestas.

El $1^{\text {o }}$ de octubre de 2019 se conmemoró el establecimiento de la RPCh; hubo manifestaciones en Hong Kong, la policía le disparó a uno de los manifestantes y un hombre 
se prendió fuego. Dos de las universidades más grandes del territorio se convirtieron en campo de batalla entre la policía y los manifestantes. Policía antimotines entró a la Universidad China de Hong Kong, en tanto que los que estaban en la Universidad Politécnica usaban bombas de gasolina y ladrillos como defensa. El pliego de demandas de los manifestantes se extendió, y además del retiro de la ley de extradición pedían una investigación sobre el uso de la fuerza por la policía, retractarse de darle la connotación de motín a las manifestaciones, liberación de los presos y una reforma política que asegurase el sufragio universal.

El $1^{\circ}$ de diciembre regresaron a protestar en Tsim Sha Tsui pidiendo que se cumplieran sus demandas. La policía los dispersó con gas lacrimógeno. El 8 de diciembre más de 800000 personas salieron a protestar, aunque de acuerdo con la policía sólo fueron $183000 . \mathrm{El} 1^{\circ}$ de enero de 2020 se realizó otra protesta multitudinaria en la que las oficinas del banco HSBC fueron atacadas (Lau 2020). En 2020, al extenderse la epidemia de coronavirus al territorio de la RAEHK, los manifestantes pidieron que se prohibiera la entrada de gente procedente de provincias chinas. Carrie Lam anunció que sólo tres de los 14 puntos de cruce serían cerrados. Hubo protestas también por las políticas seguidas por el gobierno para tratar de controlar la expansión del virus. En febrero y marzo las protestas bajaron debido a la situación sanitaria. El 18 de abril el gobierno arrestó a un grupo de políticos prodemocracia, que incluía a Jimmy Lai, Martin Lee y Margaret Ng por sus actividades políticas en 2019 (Yu y Ramzy 2020).

En la sesión anual de la Asamblea Nacional Popular, efectuada en mayo 2020, los legisladores aprobaron la Ley de Seguridad Nacional sobre Hong Kong, lo que mostraba la decisión del gobierno central de parar cualquier intento de socavar su autoridad, de tratar de convertir a la RAEHK en punta de lanza contra el régimen del PCCh. Las protestas habían llegado a un nivel en el que era necesario mostrar que Beijing tenía el control de la situación. Las declaraciones de los funcionarios chinos empezaron a subir de tono, acusando a los manifestantes de tratar de producir una situación de caos, rebasando la línea permitida. Acusó a países extranjeros de fomentar las protestas, en especial a Estados Unidos.

Ya desde el Cuarto Pleno del 19 Congreso del PCCh se había discutido la necesidad de hacer claros los puntos relativos a la seguridad en la RAEHK, sin dejar vacíos que 
pudieran llevar a interpretaciones erróneas. Además, el gobierno central tomó la decisión de nombrar a un político de línea dura, Luo Huining, como director de la Oficina Central de Enlace de Hong Kong. Luo había sido jefe del partido en la provincia de Shanxi, no tenía experiencia en asuntos de Hong Kong (Pei 2020b).

Nuevamente, el 24 de mayo los hongkoneses realizaron manifestaciones por Causeway Bay en protesta por la aprobación de la nueva ley; fue la más grande manifestación desde que se dio la crisis sanitaria. Más de 360 personas fueron arrestadas en un día. Fueron acusados de asamblea ilegal y posesión de armas. Li Ka-shing, magnate poderoso cuya fortuna es la segunda más importante en el territorio, apoyó la nueva ley (Cheung 2020).

El gobierno de la RAEHK se ha mostrado sumiso ante la autoridad del gobierno central chino y ha tratado de frenar el avance de los políticos prodemocracia que han mostrado el apoyo que tienen entre la población. En las elecciones de Concejos de Distrito del 24 de noviembre de 2019, los candidatos de ese grupo ganaron 57\% del voto popular, 391 de los 452 puestos disputados teniendo la mayoría en 17 de los 18 Concejos de Distrito (Cheng 2019). La Alianza Democrática para el Mejoramiento de Hong Kong, partido proBeijing, propuso 181 candidatos, de los cuales sólo 21 ganaron; el mismo vicepresidente del partido, Holden Chow, perdió. Precisamente por su desempeño en las elecciones, el gobierno local decidió posponer las elecciones para el Concejo Legislativo que debían celebrarse el 3 de septiembre de 2020, y que se realizarían hasta 2021.

La Ley de Seguridad Nacional fue repudiada y criticada por líderes de varios países. Estados Unidos, Reino Unido, Australia y Canadá tomaron una posición común contra ella. En una declaración conjunta pidieron a Beijing trabajar junto con el pueblo de Hong Kong para honrar los compromisos establecidos en la Declaración Conjunta Sino-Británica (Magnier y Lau 2020). Donald Trump firmó una orden ejecutiva con la que terminó el tratamiento comercial preferencial hacia Hong Kong, además promulgó un proyecto de ley en el que pide sancionar a los individuos extranjeros y bancos que contribuyeron a la erosión de la autonomía del territorio (Churchill 2020). Posteriormente, Trump impuso sanciones sobre 11 altos funcionarios de Hong Kong, entre los que se encuentran la jefa ejecutiva Carrie Lam, el jefe de policía y otros ocho que incluyen miembros del PCCh, como Luo Huining, responsable de la Oficina de Enlace del gobierno central en Hong Kong. 
En asuntos económicos, la economía de Hong Kong se debilitó, y en el segundo cuarto de 2020 el PIB cayó 9\% en comparación con el mismo periodo del año anterior. Las exportaciones cayeron $2.4 \%$. La demanda interna cayó $14.2 \%$, ya que el consumo fue desarticulado por la epidemia de covid-19. El desempleo fue de 6.2\% (Hong Kong Economy 2021).

A mediados de enero de 2020, Carrie Lam ofreció un paquete de políticas para el bienestar con un monto de HK\$10 000 millones, incluyendo extensión de días festivos, contribuciones al fondo de retiro y ayuda económica para desempleados y familias de bajos ingresos (South China Morning Post 2020).

La RAEHK se enfrenta a una situación muy complicada, pues los grupos que defienden su autonomía y rechazan una mayor cercanía con el gobierno central se siguen mostrando desafiantes; la imposición de la Ley de Seguridad Nacional les ha mostrado también que la paciencia de los líderes chinos se agotó y por tanto decidieron usar la mano dura. Al mismo tiempo, Beijing se preocupa por la situación económica de Hong Kong y está dispuesto a seguir un plan de recuperación que implique también resolver el gran problema de desigualdad de ingresos que tanto irrita a los jóvenes.

\section{CONSIDERACIONES FINALES}

En 2020, China se ha enfrentado a graves problemas generados por la epidemia, convertida en pandemia de la covid-19, no sólo dentro del país, sino también por las reacciones negativas en el exterior, principalmente de Estados Unidos. También en este año los líderes chinos comprobaron que el llamado periodo de oportunidad estratégica, en el que el país pudo aprovechar las ventajas que le ofrecía el ambiente internacional de apertura, se había terminado. Las potencias desarrolladas, al percibir su avance económico, el fortalecimiento de sus empresas en el exterior y su mayor participación en los asuntos internacionales, la confrontaron y le exigieron seguir políticas más equitativas que implicaban abrir más su mercado a productos extranjeros. Estados Unidos ha atacado a China de una manera que recuerda los años de la Guerra Fría; las declaraciones de funcionarios estadunidenses de alto nivel, rotundas y contundentes, muestran su preocupación por contener el avance de Beijing. El gobierno chino, por su parte, ha mantenido una política que se dirige hacia un mayor 
control interno y, sobre todo, en los territorios habitados por minorías étnicas como Xinjiang. Con Hong Kong se le acabó la paciencia y decidió usar mano dura para acabar con las protestas y desincentivar las actividades de grupos prodemocracia. Al mismo tiempo, estamos presenciando un regreso hacia la centralización del poder en manos de Xi Jinping y al fortalecimiento del Partido Comunista Chino.

Marisela Connelly es especialista en política exterior, historia y problemas de medio ambiente de China. Ha impartido cursos en diversas instituciones de educación superior, como la Universidad Anáhuac del Sur y Universidad de las Américas Puebla.

$\underline{\text { mconne@,colmex.mx }}$

\section{REFERENCIAS}

Albert, Eleanor. 2020a. “Trump signs Uyghur Human Rights Act Into Law.” The Diplomat, junio 18, 2020. https://thediplomat.com/2020/06/trump-signs-uyghur-human-rightsact-into-law/

Albert, Eleanor. 2020b. “China's foreign minister finishes Europe Tour.” The Diplomat, septiembre 2, 2020. https://thediplomat.com/2020/09/chinas-foreign-ministerfinishes-europe-tour/

Barr, P. William. 2020. “Attorney General William P. Barr Delivers Remarks on China Policy at the Gerald R. Ford Presidential Museum Grand Rapids, MI.” Julio 16, 2020. https://www.justice.gov/opa/speech/attorney-general-william-p-barr-delivers$\underline{\text { remarks-china-policy-gerald-r-ford-presidential }}$

Bermingham, Finbarr. 2020. "US-China trade negotiators vow to sabe phase one deal on first call during pandemic." South China Morning Post, mayo 8, 2020. https:// www.scmp.com/economy/china-economy/article/3083430/coronavirus-top-uschina-trade-negotiators-vow-save-phase-one

Chen, Frank. 2020. "Beijing braces for Covid-19 resurgence.” Asia Times, junio 15, 2020. https://asiatimes.com/2020/06/beijing-braces-for-covid-19-resurgence/ 
Cheng, Chris. 2020. "Hong Kong District Council election: Democrats take control of 17 out of 18 councils in landslide victory." Hong Kongfp, noviembre 25, 2020. https:// hongkongfp.com/2019/11/25/hong-kong-district-council-election-democrats-takecontrol-17-18-councils-landslide-victory/

Cheung, Tony. 2020. "Tycoon Li Ka-shing throws weight behind Hong Kong national security law, suggests it will ease Beijing's 'apprehension' about city.” South China Morning Post, mayo 27, 2020. https://www.scmp.com/news/hong-kong/politics/ article/3086289/tycoon-li-ka-shing-throws-weight-behind-hong-kong-national

China Daily. 2020. "Highlights of 2020 Government Work Report.” China Daily, mayo 22, 2020. https://www.chinadaily.com.cn/a/202005/22/WS5ec726fba310a8b2411577ee. $\underline{\mathrm{html}}$

Chung, Lawrence. 2020. "US diplomat Keith Krach meets Taiwanese leaders but new Dialoge still being planned." South China Morning Post, septiembre 18, 2020. https://www.scmp.com/news/china/diplomacy/article/3102162/us-diplomat-keithkrach-meets-taiwanese-leaders-new-dialogue

Churchill, Owen. 2020. “US President Donald Trump signs Hong Kong Autonomy Act, and ends the city's preferential trade status." South China Morning Post, julio 15, 2020. https://www.scmp.com/news/world/united-states-canada/article/3093200/donaldtrump-signs-hong-kong-autonomy-act-and-ends

Cong, Wang' y Li Aixin. 2020. “G20 to inject hope to world.” Global Times, marzo 26, 2020. https://www.globaltimes.cn/content/1183787.shtml

Cristiani, Dario. 2020. "The Chinese Charm Offensive Towards Italy as the Coronavirus Crisis Deepens.” China Brief, abril 1, 2020. https://jamestown.org/program/thechinese-charm-offensive-towards-ital

Deng, Iris y Celia Chen. 2020. "Trump targeted both WeChat and TikTok with US bans why then did it seem Tencent was getting an easier ride?" South China Morning Post, septiembre 18, 2020. https://www.scmp.com/tech/big-tech/article/3102034/trumptargeted-both-wechat-and-tiktok-us-bans-why-then-tencents-app 
Deutsche Welle. 2020. "EU-China summit: What really happened?" Deutsche Welle, junio 4, 2020. https://www.dw.com/en/eu-china-summit-what-really-happened/a-53688837

Dotson, John. 2020a. “The State Response to a Mystery Viral Outbreak in Central China." China Brief, enero 17, 2020. https://jamestown.org/program/the-state-response-to-amystery-viral-outbreak-in-central-china/

Dotson, John. 2020b. “The CCP’s New Leading Small Group for Countering the Coronavirus Epidemic - and the Mysterious Absence of Xi Jinping.” China Brief, febrero 5, 2020. https://jamestown.org/program/the-ccps-new-leading-small-group-for-counteringthe-coronavirus-epidemic-and-the-mysterious-absence-of-xi-jinping/

Hein von, Mathias. 2020. “Coronavirus makes Germany’s EU-China summit go virtual." Deutsche Welle, septiembre 13, 2020. https://www.dw.com/en/coronavirus-makesgermanys-eu-china-summit-go-virtual/a-54907146

Hong Kong Economy. The Government of Hong Kong Special Administrative Region. 2021. "Latest Developments.” https://www.hkeconomy.gov.hk/en/situation/development/ index.htm

Huang, Cristin. 2020. “Chinese military fires 'aircraft-carrier killer' missile into South China Sea in 'warning to the United States'." South China Morning Post, agosto 26, 2020. https://www.scmp.com/news/china/military/article/3098972/chinese-militarylaunches-two-missiles-south-china-sea-warning

Lanyon, Charley. 2020. "Coronavirus: US wants to enter Wuhan virology lab, and Trump questions China death toll." South China Morning Post, marzo 18, 2020. https:// www.scmp.com/news/china/politics/article/3080513/coronavirus-us-secretary-state$\underline{\text { mike-pompeo-seeks-access }}$

Lau, Stuart. 2020. "Xi Jinping defends China, WHO coronavirus response for first time on world stage.” South China Morning Post, mayo 18, 2020. https://www.scmp.com/ news/china/diplomacy/article/3084916/coronavirus-xi-jinping-defends-china-andwho-response-world 
Lau, Stuart y Owen Churchill. 2020. 'Xi Jinping urges 'stronger international cooperation' and quick action to fight coronavirus pandemic and stave off global recession." South China Morning Post, marzo 26, 2020. https://www.scmp.com/news/china/politics/ article/3077174/xi-jinping-urges-stronger-international-cooperation-and-quick

Magnier, Mark y Stuart Lau. 2020. "Hong Kong national security Law: US taps allies Britain, Australia and Canada to pressure China.” South China Morning Post, mayo 28, 2020. https://www.scmp.com/news/china/article/3086578/us-taps-allies-pressure-chinaover-hong-kong-national-security-law

Mai, Jun y William Zheng. 2020. “China's Communist Party elite wrap up meeting with pledge to safeguard national security in Hong Kong." South China Morning Post, noviembre 1, 2020. https://www.scmp.com/news/china/politics/article/3035818/ chinas-communist-party-elite-wrap-meeting-pledge-safeguard

Moak, Ken. 2020. "Why China might emerge stronger after Covid-19." Asia Times, mayo 19, 2020. https://asiatimes.com/2020/05/why-china-might-emerge-stronger-aftercovid-19/

Oliver, Ryan. 2020. "The CCP Response to the Wuhan Coronavirus: A Preliminary Assessment." China Brief, enero 29, 2020. https://jamestown.org/program/the-ccpresponse-to-the-wuhan-coronavirus-a-preliminary-assessment/

Pei, Minxin. 2020a. "How Has the Coronavirus Crisis Affected Xi's Power: A Preliminary Assessment." China Leadeeship Monitor, junio 1, 2020. https://www.prcleader. org/pei-1

Pei, Minxin. 2020b. "Investigation of a Death Long Feared: How China Decided to Impose its National Security Law in Hong Kong." China Leadership Monitor, septiembre 1, 2020. https://www.prcleader.org/pei-2

Pompeo, Michael, P. 2020. “Communist China and the Free World's Future.” Discurso. The Richard Nixon Presidential Library and Museum. Yorba Linda, California, julio 23, 2020. https://www.state.gov/communist-china-and-the-free-worlds-future/ 
Pottinger, Matt. 2020. "Remarks by Deputy National Security Advisor Matt Pottinger to the Miller Center at the University of Virginia.” Mayo 4, 2020. https://www.whitehouse. gov/briefings-statements/remarks-deputy-national-security-advisor-matt-pottingermiller-center-university-virginia/

Renmin Ribao 人民网. 2020. Julio 14, 2020. Julio 22, 2020. Mayo 18, 2020. Abril 4, 2020. Marzo 28, 2020.

Reuters. 2020. "US proposes new restrictions on certain exports to China." Reuters, abril 27 2020. https://www.reuters.com/article/usa-china-exports-idUSL2N2CF0I1

South China Morning Post. 2020. “Hong Kong leader Carrie Lam’s HK\$10 billion welfare package." South China Morning Post, enero 14, 2020. https://www.scmp.com/ yp/discover/news/hong-kong/article/3070860/hong-kong-leader-carrie-lams-hk10billion-welfare

Swaine, Michael D. 2020a. "Chinese Crisis Decision Making - Managing the Covid-19 Pandemic Part One: The Domestic Component." China Leadership Monitor, junio 1, 2020. https://www.prcleader.org/past-issue

Swaine, Michael D. 2020b. "Chinese Crisis Decision Making: Managing the Covid-19 Pandemic. Part Two: The International Dimension.” China Leadership Monitor, septiembre, 2020. https://www.prcleader.org/swaine-1

Swanson, Ana y Alan Rappeport. 2020. “Trump Signs China Trade Deal, Putting Economic Conflict on Pause." The New York Times, enero 15, 2020. https://www.nytimes. com/2020/01/15/business/economy/china-trade-deal.html

Talley, Ian y Lucy Craymer. 2020. "U.S. Sanctions Chinese Officials Over Hong Kong Policy-Including Carrie Lam.” The Wall Street Journal, agosto 8, 2020. https:// www.wsj.com/articles/u-s-sanctions-11-chinese-officials-over-hong-kongpolicyincluding-carrie-lam-11596812481

Tang, Frank. 2020a. "Coronavirus: China extends welfare support to vast migrant labour force amid 'unprecedented challenges'." South China Morning Post, abril 21, 2020. 
https://www.scmp.com/economy/china-economy/article/3080931/coronaviruschina-extends-welfare-support-vast-migrant-labour

Tang, Frank. 2020b. "China's economic strategy shift shows Xi Jinping is preparing for 'worst case scenario', analysts say.” South China Morning Post, mayo 25, 2020. https://www.scmp.com/economy/china-economy/article/3085969/chinas-economicstrategy-shift-shows-xi-jinping-preparing

Wang, Orange. 2020. “Coronavirus: can China's economy rebound in 2020 second quarter with the rest of the world still in trouble?" South China Morning Post, abril 7, 2020. https://www.scmp.com/economy/china-economy/article/3078807/coronavirus-canchinas-economy-rebound-2020-second-quarter

Watts, Gordon. 2020. "China faces triple whammy amid Covid-19 crisis.” Asia Times, abril 30, 2020. https://asiatimes.com/2020/04/china-faces-triple-whammy-amid-covid-19$\underline{\text { crisis/ }}$

Wong, Bryan. 2020. “China's Mask Diplomacy.” The Diplomat, marzo 25, 2020. https://hediplomat.com/2020/03/chinas-mask-diplomacy/

Wong, Edward. 2020. "U.S. Pushes Large Arms Sale to Taiwan, Including Jet Missiles That Can Hit China." The New York Times, septiembre 17, 2020. https://www. nytimes.com/2020/09/17/us/politics/us-arms-sale-taiwan-china.html

Wu, Wendy, Kristin Huang y Sarah Zheng. 2020. “US-China talks: Mike Pompeo's sevenhour meeting with Yang Jiechi 'helps atmosphere' - but statements reveal divisions.” South China Morning Post, junio 18, 2020. https://www.scmp.com/news/china/ diplomacy/article/3089672/us-china-talks-pompeos-seven-hour-meeting-yang-helps

Xinhua. 2019. "2-Late village official posthumously honored as outstanding Party member." Xinhua, octubre 10, 2019. http://www.xinhuanet.com/english/2019-10/10/c_138461 743.htm

Xinhua. 2020a. "Factbox: China's fight against novel coronavirus outbreak.” Xinhua, febrero 12, 2020. http://www.xinhuanet.com/english/2020-02/12/c 138775763.htm 
Xinhua. 2020b. "People's war: China's response to Covid-19." Xinhua, abril 4, 2020. http://www.xinhuanet.com/english/2020-04/04/c_138946047.htm

Yu, Elaine y Austin Ramzy. 2020. “Amid Pandemic, Hong Kong Arrests Major ProDemocracy Figures." The New York Times, abril 18, 2020. https://www.nytimes. com/2020/04/18/world/asia/hong-kong-arrests.html

Zhuang, Pinghui y Victor Ting. 2020. "Beijing battles 'explosive coronavirus outbreak' as food market cases mount." South China Morning Post, junio 16, 2020. https://www. scmp.com/news/china/society/article/3089042/coronavirus-beijing-marketoutbreak-cases-rise-79 